\title{
Endoscopy of the lacrimal system
}

\author{
Klaus Müllner, Elisabeth Bodner, Geva E Mannor
}

Department of Ophthalmology, Box 1183, University of Graz,

Auenbruggerplatz 4, A- 8036 Graz, Austria K Müllner

E Bodner

Department of Ophthalmology, Mt Sinai Hospital, Gustave Levy Place, New York, USA G E Mannor

Correspondence to: Dr Müllner.

Accepted for publication 19 March 1999

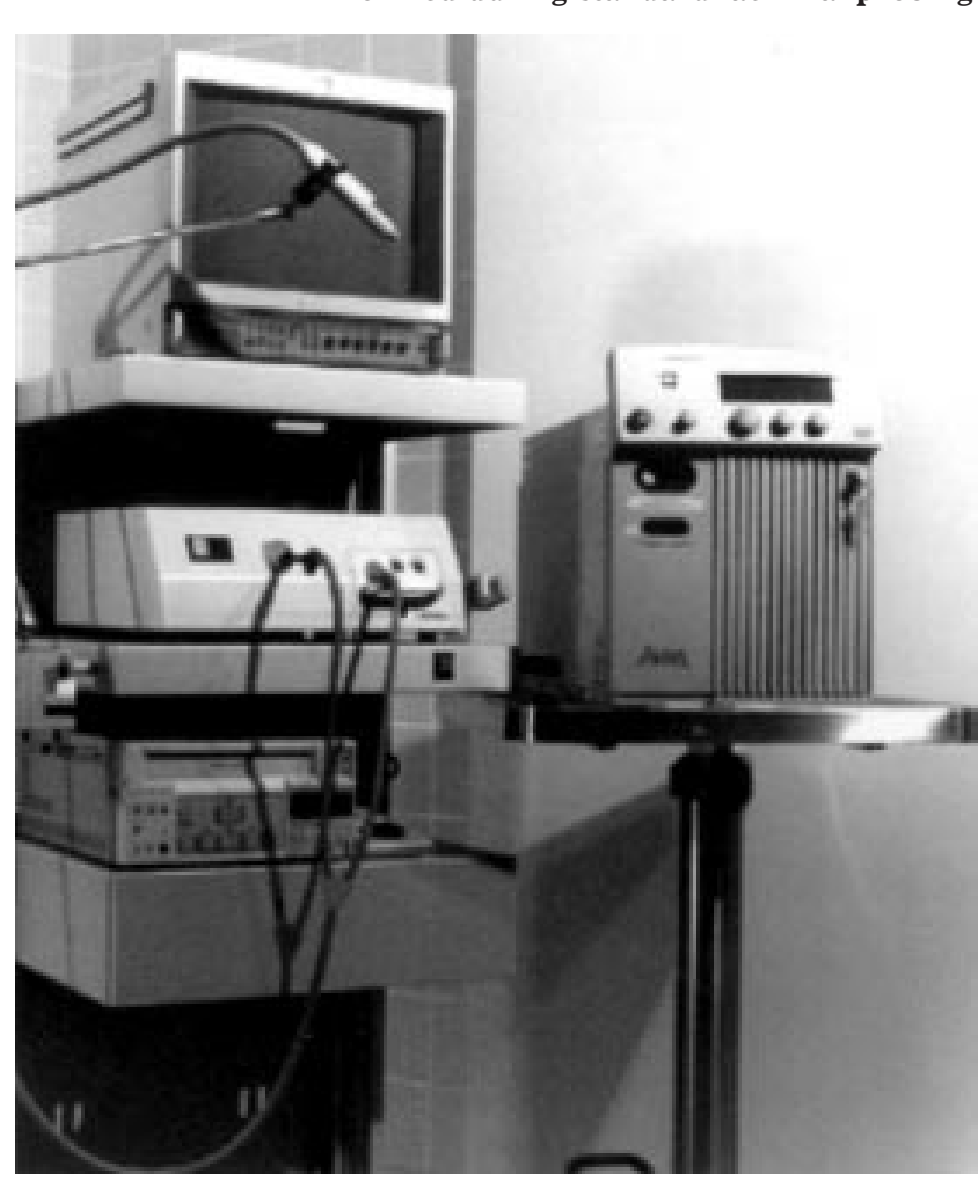

Figure 1 Endoscopy unit consisting of xenon light source, video camera with ocular

attachment, and miniature CCD camera.

Abstract

Backgroundlaim-Until recently, diagnosis of disorders of the lacrimal system has depended on digital dacryocystography and on clinical examinations such as the fluorescein dye test, lacrimal probing, and irrigation. The lacrimal system and its mucous membranes can now be viewed directly with a lacrimal endoscope. While the first endoscopes were rigid and limited by poor picture quality in axial illuminations, the new generation of endoscopes are a great leap forward for new diagnostic and therapeutic approaches.

Methods-132 patients ranging in age from 8 months to 73 years with nasolacrimal obstruction were referred to the lacrimal department. Diagnostic lacrimal imaging utilising various small calibre endoscopes less than $0.5 \mathrm{~mm}$ in external diameter was performed. The endoscopes are coupled to specially designed lacrimal probes as well as a CCD camera and a video recorder. The imaging was performed during standard lacrimal probing and irrigation in an outpatient clinic setting in 120 of 132 patients

Results-All patients reported the pain of endoscopy as being similar to that of standard lacrimal probing and irrigation. No adverse effects such as bleeding or lacrimal perforation were noted. Endoscopic manipulation was not too difficult and the picture quality, depth of focus, and illumination were satisfactory in all cases. The most common site of stenosis was the nasolacrimal duct (59 patients), followed by the lacrimal sac (39 patients) and the canaliculi (34 patients). In 25 patients, partial obstruction, rather than complete stenosis, was visualised as a narrow lumen, which widened during irrigation. In 14 of 28 patients, obstruction was due to canalicular submucosal folds and was removed with laser. In addition, the colour and consistency of the lining mucosa correlated with type of obstruction. Normal mucosa is smooth and light pink in colour. Inflammatory changes manifest as thickened and reddish grey mucosa. More complete stenosis is shown as fibrotic plaques with grey white inelastic membranes.

Conclusion-Lacrimal endoscopy is a new, non-invasive method used to view directly and localise obstructions precisely. It allows differentiation between inflammatory, partial, and complete stenosis. Endoscopy enables one to choose the appropriate surgical therapy for patients. Patients tolerated the procedure well without any adverse reactions or effects. While it may not replace standard probing and irrigation, this technique is an extremely useful adjunct in determining the proper surgical modality, ease, and tolerance of the endoscopic manipulation by patients, and obtaining sharp and clear images of the nasolacrimal outflow system anatomy and pathology. Differentiation of various types of obstruction by precise location and severity can be achieved.

(Br f Ophthalmol 1999;83:949-952)

Disorders of the lacrimal drainage system manifest as epiphora and recurrent infections with mucopurulent discharge. Severe lacrimal infections can be very debilitating and cause severe visual and functional disability. In order to select the proper surgical procedure, it is extremely important to know the precise cause and location of the nasolacrimal obstruction. Uncomplicated infections are treated with topical antibiotic drops and irrigation of the lacrimal duct. Postinfectious adhesions, stenosis, or scar tissue formation in the canaliculus 


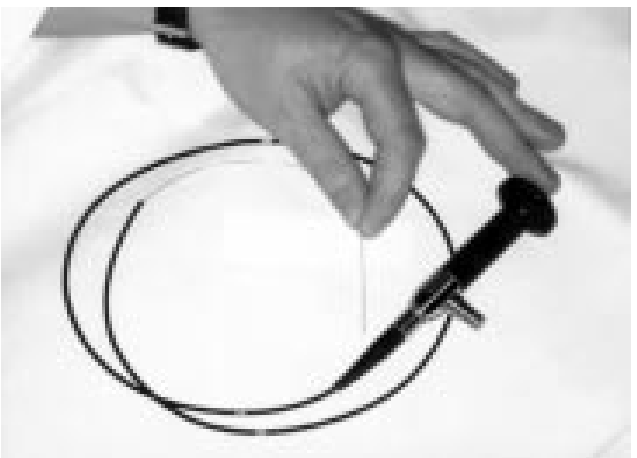

Figure 2 Mini endoscope with outer diameter $0.5 \mathrm{~mm}$.

are treated with probing and possibly graduated dilatation. Often surgery is required to bypass the nasolacrimal obstruction. ${ }^{1}$ Depending on the exact location and severity of the lacrimal blockage, various types of lacrimal procedures are required including dacryocystorhinostomy (DCR), and canalicular (DCR or Jones) tube surgery. ${ }^{1}$

To locate the obstruction before surgery, diagnostic techniques such as simultaneous probing and high pressure irrigation, dacryocystography, digital subtraction angiography,

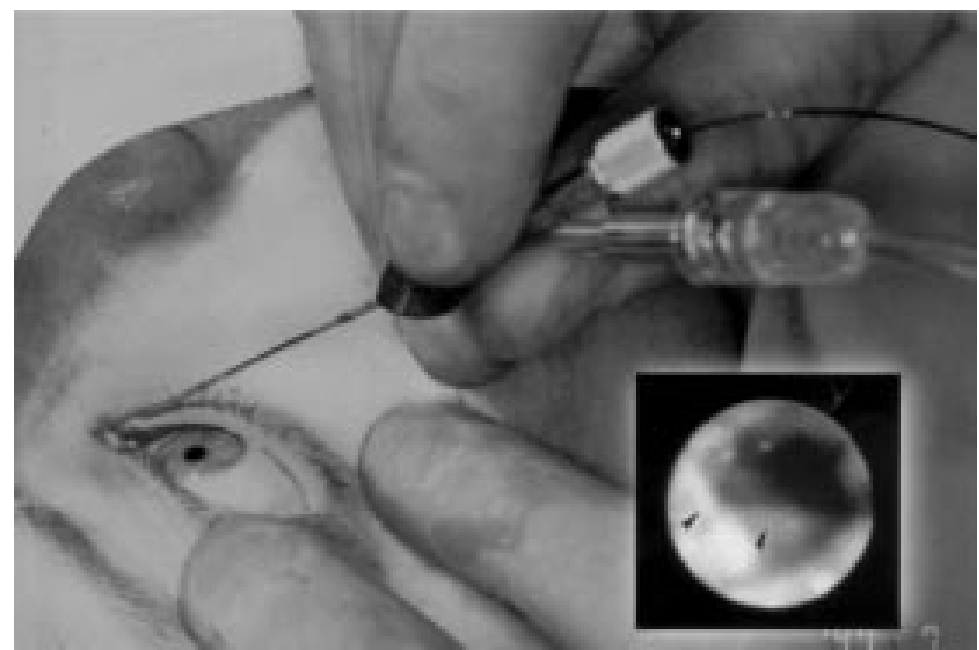

Figure 3 Endoscope in place, inset shows a lower canaliculus with debris and submucosal folds (arrows).

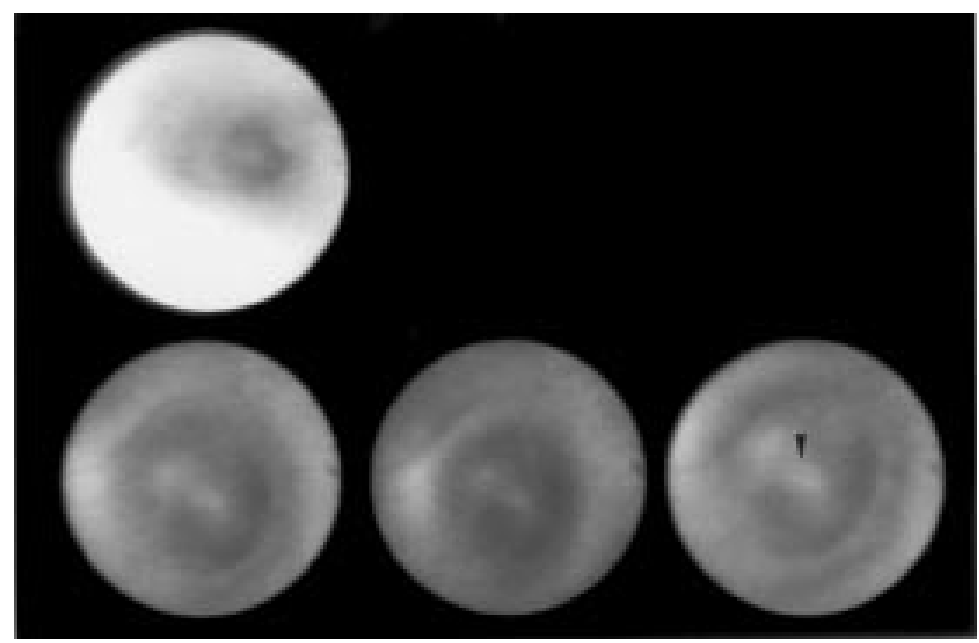

Figure 4 Lower canaliculus with grey-white membrane occluding whole lumen of the canaliculus. Resistance felt during probing (membrane marked by arrowhead). and echographic examination have been employed. ${ }^{2-6} \mathrm{Up}$ to now, direct evaluation of lacrimal disorders has been limited to examination of the eyelids and puncta. Lacrimal endoscopes allow direct visualisation of the canaliculi, lacrimal sac, nasolacrimal duct, and their mucous membranes. Initially, lacrimal endoscopes were rigid and limited by poor illumination. Newer lacrimal endoscopes with better physical and optical properties can now produce excellent lacrimal images.

\section{Materials and methods}

A total of 132 patients ranging in age between 8 months and 73 years were examined. Two flexible endoscopes (Marathon Medical, Austria) were employed. One endoscope has an outer diameter of $0.3 \mathrm{~mm}, 1800$ pixels, 22 light fibres, and a 70 degree field of view; the other has an outer diameter of $0.5 \mathrm{~mm}, 3000$ pixels, 46 light fibres, and a 70 degree field of view. The entire unit consists of a xenon light source (Lisa Basic, xenon light source, Medexxa Gmbh, Germany), a video camera (Sony videocamera, Sony Gmbh, Japan), with an ocular attachment, and a miniature charge coupled device (CCD) camera system with a monitor (Sony HR Trinitron) and videorecorder (Sony video recorder, SVO $9500 \mathrm{MDP}$ ) (Fig 1). This system can be combined with modified Jünemann probes which either have just two attachments for endoscopy and irrigation or, depending on the model, a third attachment to couple a laser fibre (Fig 2). The internal and external diameters of the first probe are 0.6 and $0.8 \mathrm{~mm}$ and those of the laser coupled probe are 0.7 and $1.1 \mathrm{~mm}$, respectively. A titanium-potassium laser with a specially developed and designed adapter can be coupled to the endoscope.

Seven children whose age ranged between 6 and 28 months and five adult patients were examined under general anaesthesia before planned DCR surgery. In another 120 patients, diagnostic endoscopy was performed in an outpatient setting with topical anaesthesia (Benoxinate eye drops) and local anaesthesia (pericanalicular and perisaccal xylocaine $2 \%$ ). After irrigating and cleansing the lower canaliculus, the punctum was dilated and the endoscope was inserted. In full view and with steady gentle irrigation, the endoscope was slowly advanced toward the canaliculus. Upon reaching the lateral wall of the lacrimal sac, the endoscope was held upright and advanced as in lacrimal duct probing towards the nasal meatus and into the nose under the inferior turbinate. Continuous irrigation during the whole endoscopy is necessary for good imaging. We did not use any viscoelastic substance to enlarge the canaliculi. Stenosis and scar formation of the lacrimal drainage system, as well as inflammation of the mucous membranes, were localised and recorded during the examination. Normal distension of the lacrimal system is seen as widening of the lumen during irrigation and easy handling of the endoscope. The stenosis could not be widened during irrigation and the endoscope met with a level 


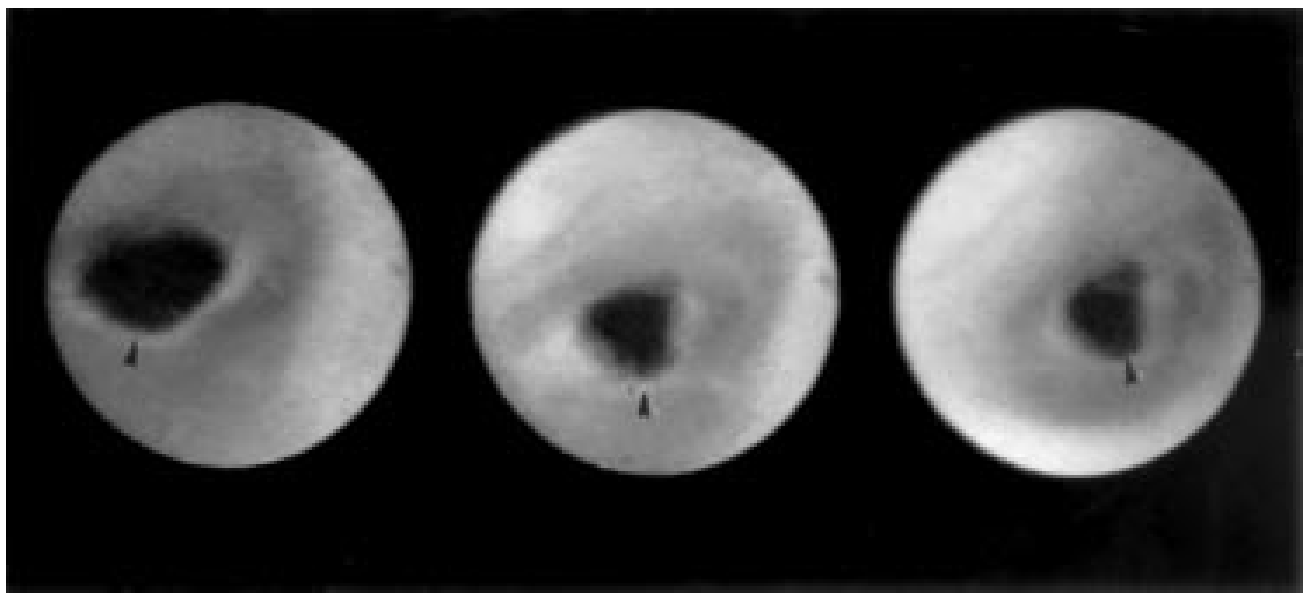

Figure 5 Submucosal fold (marked by arrowheads) simulating stenosis, could be lasered. Seen during endoscopy as a strong white mucosal fold.

of resistance similar to that encountered with conventional probing of the lacrimal system (see Figs 3-6).

\section{Results}

The endoscope was easily inserted into the lower canaliculus after dilatation of the punctum. Picture quality, depth of focus and axial illumination were very good in all cases. In 25 of 132 patients the suspected stenosis was identified as partial obstruction when a narrow lumen enlarged with irrigation. The site of stenosis was precisely located, commonly in the nasolacrimal duct (Table 1). Stenosis presented as whitish grey inelastic membranes in the canaliculus, nasolacrimal sac, and duct, and were differentiated from mucosal folds and treated surgically. These submucosal folds are seen as thick grey strictures.
The folds were treated with a laser and 18 of 25 patients have remained free of symptoms. Seven patients had a restenosis and a conventional DCR was performed. Heavy debris and secretions were differentiated from complete stenosis by their clearance with irrigation.

The normal mucosa of the lacrimal system is usually smooth, light pink, and moves during irrigation. Postinflammatory conditions showed thickened mucosa of a more reddish grey colour with large papillae.

No complications such as perforation, postoperative bleeding, or inflammation occurred during any of the endoscopic examinations. All patients who had been examined as outpatients described the endoscopy as not being painful, but $30 \%$ did find it as uncomfortable as lacrimal irrigation. Sixty three patients, whose endoscopy was performed in an outpatient

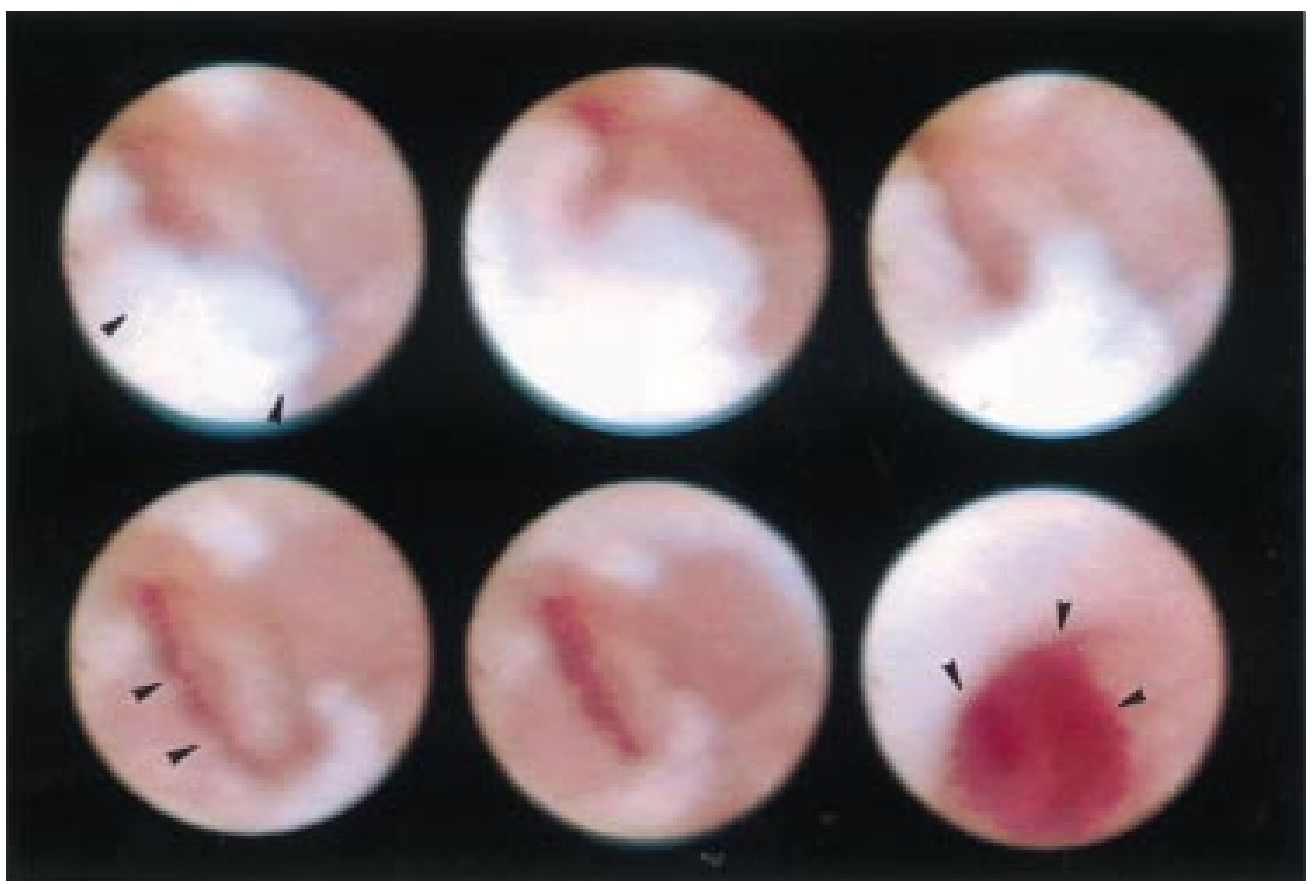

Figure 6 Lower canaliculus. Top three pictures show mucus and debris (arrowheads) occluding the canaliculus. Bottom left and middle pictures show very narrow lumen (arrowheads) after cleansing the canaliculus. Bottom right shows widening of the lumen under pressure irrigation (arrowheads). 
Table 1 Endoscopic location of lacrimal and nasolacrimal stenosis in 132 patients

\begin{tabular}{lc}
\hline Location & Number (\%) \\
\hline Canaliculus & $34(25.8)$ \\
Lacrimal sac & $39(29.5)$ \\
Nasolacrimal duct & $59(44.7)$ \\
Total & $132(100)$ \\
\hline
\end{tabular}

clinic setting without adverse effects, returned home shortly afterwards.

\section{Discussion}

In 1992 Fein et al reported endoscopy of the lacrimal outflow system in a small number of patients. They used two different endoscopes which provided useful images of the lacrimal outflow system during simultaneous viewing of the upper and lower canaliculus. ${ }^{7}$ Singh et al described endoscopic visualisation of the nasolacrimal system in four cadavers. ${ }^{8}$ They felt that the endoscopes were too flexible to be inserted into the upper canaliculus and the nasolacrimal duct. Kuchar et al described their experience with specially designed and modified endoscopes. ${ }^{9}$ Yet, the picture quality was not satisfactory. The endoscopes described here are thin, flexible, and are used with a modified Jünemann probe. They enable examination of the whole length of the lacrimal outflow system without additional equipment.

In all 132 patients endoscopic examination provided excellent viewing of the lacrimal system without limiting the quality of the images. Endoscopy allows the exact localisation and the direct viewing of the cause of epiphora, chronic inflammation, or dacryocystitis. Examinations such as digital subtraction dacryocystography which require the use of a complex examination unit (coupled to an angiography unit) are becoming increasingly unnecessary since they only allow indirect evaluation of the lacrimal drainage system. ${ }^{5}$ It does not reveal changes in the mucous membranes such as oedematous inflammation or scar formation

Lacrimal irrigation with or without high pressure and dye tests cannot be replaced by endoscopy because it is a rapid and easy method to determine lacrimal patency. However, endoscopy is the best method for precise localisation and direct evaluation of the lacrimal system, and subsequent planning of surgical treatment.

The diameter of the punctum ranges between $0.3 \mathrm{~mm}$ in children and $0.5 \mathrm{~mm}$ in adults, while the canaliculus has a diameter of $0.5 \mathrm{~mm}$ and elastic walls. With miniaturisation of endoscopes (outer diameters $0.3 \mathrm{~mm}$ or 0.5 $\mathrm{mm}$ ) and a modified Jünemann probe (outer diameters $1.1 \mathrm{~mm}$ or $0.7 \mathrm{~mm}$ ) endoscopic examination is possible in practically all patients. Excellent viewing of the drainage system is possible as aresult of improvement in the optic fibres and in light quality. Pathological changes such as mucosal strictures, scars, and stenosis can be visualised directly and differentiated from partial obstruction by viewing mucosal inflammatory changes such as mucosal folds. Stenosis can also be differentiated from debris and mucous secretions which are easily removed. When probing congenital duct obstruction, the stenosis can be dilated visually so that injuries and perforation of the mucous membranes is avoided. Moreover, the precise localisation of various types of obstruction enables the lacrimal surgeon to choose the appropiate surgical procedure. Initial difficulties in handling of the instruments, evaluation of the mucous membranes, and diagnosis of pathological changes improves with experience and recognition of certain landmarks.

Currently, endoscopy is mainly used to localise lacrimal drainage obstruction and to facilitate the choice of the appropriate therapeutic procedure. However, endoscopic examinations may pave the way for new forms of therapy. Various types of lasers such as high energy argon lasers, holmium YAG, carbon dioxide lasers, and titanium-potassium laser have been used for endonasal endoscopic laser DCR. ${ }^{10-14}$ Christenbury reported a translacrimal laser dacryocystorhinostomy with an argon laser. ${ }^{11}$ His success rate was about $60 \%$, and his main problem was bone penetration and osteotomy formation. We are still searching for a laser powerful enough to create a large bone window. Levin and Stermogipson reported an anatomical study with a titaniumpotassium laser to create a bony opening up to $4 \times 6 \mathrm{~mm} .{ }^{14}$ Further study will elucidate the appropriate lasers for osteotomy formation.

The advantage of endoscopic examination is direct visualisation and precise localisation of the lacrimal drainage system and its mucous membranes. The decision about whether a DCR, opening the stenosis with a laser, or gradual dilatation is the most appropriate can then be made. Endoscopy can be safely performed in an outpatient setting without adverse effects. With this method one can expect improved diagnostic efficiency and a more appropriate choice of surgical procedure.

The authors have no financial interests in any of these products mentioned in this article.

1 Hurwitz JH, ed. The lacrimal system. Philadelphia: Lippincott Raven, 1996.

2 Mannor GE, Millman AL. The prognostic value of preoperative dacryocystography in endoscopic intranasal dacryocystorhinostomy. Am $\mathcal{F}$ Ophthalmol 1992;113:134-6.

3 Millman AL, Liebskind A, Putterman AM. Dacryocystography. The technique and its role in the practice of ophthalmology. Radiol Clin N Am 1987;25:781-4.

4 Von Denffer H, Dresseler J. Radionuclide dacryocystography for demonstrating obstructions of the lacrimal drainage apparatus. Graefes Arch Clin Exp Ophthalmol 1974;191:321-8.

5 Steinkogler FJ, Karnel F, Canigiani G. Digital dacryocystography. Klin Monatsbl Augenheilkd 1987;191:55-7.

6 Rochels R, Lieb W, Nover A. Echographic diagnosis in disRochels R, Lieb W, Nover A. Echographic diagnosis in dis-
eases of the efferent tear ducts. Klin Monatsbl Augenheilkd eases of the efferent

7 Fein W, Daykhovsky L, Papaioannou T, et al. Endoscopy of the lacrimal outflow system. Arch Ophthalmol 1992;110: 1748-50.

8 Singh AD, Singh A, Whitmore I, et al. Endoscopic visualisation of the nasolacrimal system: an experimental study. $\mathrm{Br}$ Ophthalmol 1992;76: 663-7.

9 Kuchar A, Novak P Fink M, et al. Recent developments in lacrimal duct endoscopy. Klin Monatsbl Augenheilkd 1997; 210:23-6.

10 Massaro BM, Gonnering RS, Harris GJ. Endonasal laser dacryocystorhinostomy. Arch Ophthalmol 1990;108:1772-6. Christenbury JD. Translacrimal laser dacryocystorhinostomy. Arch Ophthalmol 1992;110:170-1.

12 Gonnering RS, Lyon DB, Fisher JC. Endoscopic laserassisted lacrimal surgery. Am F Ophthalmol 1991;111:152-7.

13 Seppa H, Grenman R, Hartikainen J. Endonasal $\mathrm{CO}_{2}-$ Nd:YAG laser dacryocystorhinostomy. Acta Ophthalmol 1994;72:703-6.

14 Levin PS, Stermogipson J. Endocanalicular laser assisted dacryocystorhinostomy. An anatomic study. Arch Ophthalmol 1992;110:1488-90. 